\title{
A Novel Sensor Based on Ag Nanoparticles Functionalized with Poly-Acid Chrome Blue K and Graphene for the Sensitive Determination of Diclofenac Sodium
}

\author{
Qing Huang ${ }^{1}$, Xiaokun Li ${ }^{1,}{ }^{*}$, Suxiang Feng ${ }^{1}$, Wenfeng Zhuge ${ }^{1}$, Jinyun Peng ${ }^{2}$, Xiaoting Li $^{2}$ \\ ${ }^{1}$ School of Pharmacy, Henan University of Traditional Chinese Medicine, Zhengzhou 450046, China \\ ${ }^{2}$ College of Chemistry and Chemical Engineering, Guangxi Normal University for Nationalities, \\ Chongzuo 532200, China \\ *E-mail: $\underline{\text { li96052122@126.com }}$
}

doi: $10.20964 / 2019.02 .34$

Received: 10 May 2018 / Accepted: 20 June 2018 / Published: 5 January 2019

\begin{abstract}
$\mathrm{Ag}$ nanoparticles functionalized with poly-acid chrome blue $\mathrm{K}$ and graphene (Ag-poly-ACBK@Gr) were successfully fabricated on the surface of a glassy carbon electrode using layer-by-layer electropolymerization. The surface structure of the synthesized modified glassy carbon electrode was characterized by scanning electron microscopy. The electrochemical behaviours of diclofenac sodium (DS) at the Ag-poly-ACBK@Gr-modified electrode were investigated by cyclic voltammetry and differential pulse voltammetry. It was found that the prepared sensor exhibited a cathodic peak at 0.78 $\mathrm{V}$ with higher peak current response compared to the related modified electrodes. Under optimal conditions, the sensor for the determination of DS exhibits a good linear relationship between the peak current and DS concentration in the range from 0.1 to $40 \mu \mathrm{M}$, and the equation is $\operatorname{Ip}(\mu \mathrm{A})=7.23 \times$ $10^{3} c(\mu \mathrm{M})+3.46 \times 10^{-2}(\mathrm{R}=0.9955)$ with the estimated limit of detection of $34.2 \mathrm{nM}(\mathrm{S} / \mathrm{N}=3)$. The Ag-poly-ACBK@Gr-modified glassy carbon electrode with high sensitivity and excellent stability and selectivity was successfully applied to detect DS in real drugs and human urine at the recoveries ranging from 99.60 to $101.84 \%$.
\end{abstract}

Keywords: Ag-poly-ACBK@Gr; Diclofenac sodium; Electrochemistry

\section{FULL TEXT}

(C) 2019 The Authors. Published by ESG (www.electrochemsci.org). This article is an open access article distributed under the terms and conditions of the Creative Commons Attribution license (http://creativecommons.org/licenses/by/4.0/). 